\title{
Aa. Vv. Littérature et philosophie mêlées
}

\section{Marco Stupazzoni}

\section{(2) OpenEdition}

\section{Journals}

\section{Edizione digitale}

URL: http://journals.openedition.org/studifrancesi/33358

DOI: 10.4000/studifrancesi.33358

ISSN: 2421-5856

\section{Editore}

Rosenberg \& Sellier

\section{Edizione cartacea}

Data di pubblicazione: 1 décembre 2005

Paginazione: 656

ISSN: 0039-2944

\section{Notizia bibliografica digitale}

Marco Stupazzoni, «Aa. Vv. Littérature et philosophie mêlées», Studi Francesi [Online], 147 (XLX | III) |

2005, online dal 30 novembre 2015, consultato il 18 avril 2021. URL: http://journals.openedition.org/ studifrancesi/33358; DOI: https://doi.org/10.4000/studifrancesi.33358

\section{Questo documento è stato generato automaticamente il 18 avril 2021.}

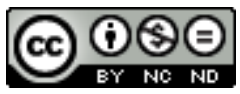

Studi Francesi è distribuita con Licenza Creative Commons Attribuzione - Non commerciale - Non opere derivate 4.0 Internazionale. 


\title{
Aa. Vv. Littérature et philosophie mêlées
}

\author{
Marco Stupazzoni
}

\section{NOTIZIA}

Aa. Vv. Littérature et philosophie mêlées, «Romantisme», n 124, 2e trimestre 2004, pp. 160.

1 Di questo interessante fascicolo monografico curato da Gisèle SÉGINGER («Introduction, pp.3-18) e dedicato ai rapporti tra letteratura e filosofia in Francia nella prima metà dell'Ottocento, segnaliamo gli studî che trattano in modo significativo dell'opera di Balzac.

2 Éric BORDAS («Romanesque et énonciation "philosophique” dans le récit», pp. 53-69) sottolinea la ricettività del romanzo ottocentesco nei confronti del discorso filosofico: partendo da La Nouvelle Héloïse di Rousseau, l'autore esamina, attraverso l'ampio spettro della produzione narrativa di Balzac e di George Sand, la nuova modulazione "drammatica" del "discours philosophique" nel romanzo che, conclude l'autore, "aboutit à une philosophie du romanesque, qui est aussi un romanesque de la philosophie» (p. 69).

3 Max ANDRÉoli («Esquisse d'un parallèle entre les philosophies de Balzac et de Hugo», pp. 71-88) stabilisce interessanti analogie tra le idee e i temi filosofici che formano i sistemi di pensiero soggiacenti alle opere di Balzac e di Hugo. Nei due scrittori, è evidente la presa di coscienza delle insufficienze dei metodi conoscitivi proprî del pensiero razionale e della scienza per spiegare $\mathrm{i}$ moti dello spirito e i misteri dell'infinito. Altrettanto significativa è la vocazione di entrambi a costruire il proprio universo letterario come un'opera che, pur nella sua estrema varietà, trovi in sé ed esprima il senso profondo (storico, filosofico, artistico) dell'unità.

4 Myriam Roman («Avatars romanesques du penseur chez Mme de Staël, Balzac et Hugo», pp. 89-102) studia la rinascita del personaggio "penseur" in alcune opere letterarie 
francesi del primo Ottocento (Corinne, Louis Lambert, Les Travailleurs de la mer) la cui importanza risiede nel fatto di essere i simboli di una nuova e problematica concezione di filosofia applicata all'affettività, alla materialità, al sogno e alla follia. 